\section{Agoraphobia in an evolutionary context}

I was interested in Bracha et al's postulation that agoraphobia might be a result of evolutionary bias towards safety-seeking among plain-living descendants. I am keen on evolutionary explanations of psychiatric phenomena, despite the fact that they cannot be proved, because they make so much sense to patients. They also allow a different perspective on distressing difficulties, even suggesting some benefit in what had previously been experienced as purely negative phenomena - for example, anxiety conferring a safety advantage in past millennia.

However, I am not so convinced by the explanation given. Many of the patients I see with agoraphobia are most phobic not about open spaces, but about places where they might be seen by others to 'embarrass themselves', usually by vomiting, fainting, or screaming out loud. Their overwhelming desire to return home seems to be as much about being hidden from others of the same species as about safety from predators. The explanation I favour is that signs of illness would possibly result in, at best, being excluded from the tribe, and, at worst, being killed and disposed of, both because of the risk of infecting or damaging the rest of the tribe. This is also, of course, related to past and present stigma and understanding of mental illness and unusual phenomena.

My patients have found this a very helpful, rational explanation which has helped them to start making sense of that feels like irrational, uncontrollable behaviour. I will now also include Bracha et al's explanation and see which has more face validity.

Bracha, H. S.., Lenze, S. M. \& Shelton, J. (2006)

Primary agoraphobia as a specific phobia (letter). British Journal of Psychiatry, 189, 470.

G. Cornish Surrey and Borders Partnership NHS Trust, Epsom, Surrey, UK. Email:

Glenn.cornish@sabp.nhs.uk

doi: 10.I192/bjp.190.4.364

Authors'reply: The patients Cornish describes probably have the post-traumatic stress disorder-like secondary agoraphobia (also known as conditioned, acquired, post-traumatic, memory-trace-overconsolidation-based agoraphobia), not the rarer primary (also known as innate prepotentiated) agoraphobia.

As we have proposed (Bracha, 2006; Bracha et al, 2006a), both primary and secondary agoraphobia should be taken out of the panic disorder section of DSM-V/ICD-11. Primary agoraphobia (i.e. with no prior Criterion A traumatic event) should be categorised with the other innate specific phobias and secondary (post-traumatic) agoraphobia should be categorised alongside (a more narrowly defined) post-traumatic stress disorder (PTSD) in a new sub-category of anxiety/ stress/fear disorders entitled 'overconsolidational fear disorders.' Contrary to dogma, evolutionary hypotheses are testable (Bracha et al, 2005; Bracha, 2006; Bracha \& Hayashi, 2006; Bracha et al, 2006b).

Panic attacks away from home are not the sole Criterion A event which (if untreated) are often followed by secondary (memory-trace-overconsolidation-based) agoraphobia. Secondary agoraphobia frequently follows embarrassing experiences away from home, related to psychiatric and non-psychiatric conditions such as chronic motor or vocal tic disorder, trichotillomania, narcolepsy, grand mal seizures, etc. Criterion A experiences ('events') such as being bullied, ridiculed, threatened or physically assaulted by school or neighbourhood peers are also often followed by the PTSD-like secondary agoraphobia.

Another diagnosis Cornish should consider is social phobia (i.e. innate fear of simultaneous visual scrutiny by a large group of strangers). During much of the human era of evolutionary adaptedness, being stared at by a large group of nonsmiling, non-kin conspecifics was more likely than not to be followed by negative consequences (Bracha, 2006). Evolution is not forward looking and could not anticipate a future where being stared at by a large group of non-smiling strangers might be followed by receiving an honorarium rather than by injury or death.

Most importantly, both the dimensional and categorical approaches planned for DSM-V/ICD-11 should include an evolution-inspired 'innateness axis' modelled on Axis V (the global assessment of functioning axis). The dimensional innateness axis score would reflect the clinician's estimate (based on past psychiatric history, genetic history, age at onset, etc.) of the likely 'hardwiredness' of a particular patient's symptoms (with low scores indicating a mostly post-traumatic, overconsolidational aetiology and high scores indicating a mostly evolutionarily hardwired aetiology).

Bracha, H. S. (2006) Human brain evolution and the "neuroevolutionary time-depth principle": implications for the reclassification of fear-circuitry-related traits in DSM-V and for studying resilience to warzone-related posttraumatic stress disorder. Progress in NeuroPsychopharmacology and Biological Psychiatry, 30 827-853.

Bracha, H. S. \& Hayashi, K. (2006) Resilience in the aftermath of terrorism and during warzone exposure: is it religiousness or is it number of blood relatives? Journal of Clinical Psychiatry, 67, I146-1154.

Bracha, H. S., Yoshioka, D. T., Masukawa, N. K., et al (2005) Evolution of the human fear-circuitry and acute sociogenic pseudoneurological symptoms: the Neolithic balanced-polymorphism hypothesis. Journal of Affective Disorders, 88, 119-129.

Bracha, H. S., Lenze, S. M. \& Shelton, J. (2006a) Primary agoraphobia as a specific phobia. British Journal of Psychiatry, 189, 470.

Bracha, H. S., Bienvenu, O. J. \& Eaton, W. W. (2006b) Testing the Paleolithic-human-warfare hypothesis of blood-injection phobia in the Baltimore ECA Follow-Up Study - towards a more etiologically-based conceptualization for DSM-V. Journal of Affective Disorders, 97, I-4.

\section{H. S. Bracha, J. M. Shelton, S. M. Lenze}

National Center for Posttraumatic Stress Disorder, Department of Veterans Affairs, Pacific Islands Health Care System,

Spark M. Matsunaga Medical Center and Asia-Pacific Center for Biosecurity, Disaster and Conflict Research, Asia-Pacific University of Hawaii School of Medicine, Honolulu, USA. Email: h.bracha@med.va.gov doi: 10.1192/bjp.190.4.364a 